\title{
Pain-related beliefs are associated with arm function in persons with frozen shoulder
}

Citation for published version (APA):

De Baets, L., Matheve, T., Traxler, J., Vlaeyen, J. W. S., \& Timmermans, A. (2020). Pain-related beliefs are associated with arm function in persons with frozen shoulder. Shoulder \& Elbow, 12(6), 432-440. https://doi.org/10.1177/1758573220921561

Document status and date:

Published: 01/12/2020

DOI:

10.1177/1758573220921561

Document Version:

Publisher's PDF, also known as Version of record

Document license:

Taverne

Please check the document version of this publication:

- A submitted manuscript is the version of the article upon submission and before peer-review. There can be important differences between the submitted version and the official published version of record.

People interested in the research are advised to contact the author for the final version of the publication, or visit the DOI to the publisher's website.

- The final author version and the galley proof are versions of the publication after peer review.

- The final published version features the final layout of the paper including the volume, issue and page numbers.

Link to publication

\footnotetext{
General rights rights.

- You may freely distribute the URL identifying the publication in the public portal. please follow below link for the End User Agreement:

www.umlib.nl/taverne-license

Take down policy

If you believe that this document breaches copyright please contact us at:

repository@maastrichtuniversity.nl

providing details and we will investigate your claim.
}

Copyright and moral rights for the publications made accessible in the public portal are retained by the authors and/or other copyright owners and it is a condition of accessing publications that users recognise and abide by the legal requirements associated with these

- Users may download and print one copy of any publication from the public portal for the purpose of private study or research.

- You may not further distribute the material or use it for any profit-making activity or commercial gain

If the publication is distributed under the terms of Article $25 \mathrm{fa}$ of the Dutch Copyright Act, indicated by the "Taverne" license above, 


\section{Pain-related beliefs are associated with arm function in persons with frozen shoulder}

Shoulder \& Elbow 2020, Vol. I2(6) $432-440$ (C) The Author(s) 2020 Article reuse guidelines: sagepub.com/journals-permissions DOI: 10.1 I 177/175857322092/56 journals.sagepub.com/home/sel

@SAGE

\section{De Baets' (D, T Matheve', J Traxler ${ }^{2,3}$, JWS Vlaeyen ${ }^{2,3}$ and A Timmermans'}

\section{Abstract}

Background: Frozen shoulder is a painful glenohumeral joint condition. Pain-related beliefs are recognized drivers of function in musculoskeletal conditions. This cross-sectional study investigates associations between pain-related beliefs and arm function in frozen shoulder.

Methods: Pain intensity, arm function (Disabilities of the Arm, Shoulder and Hand Questionnaire (DASH)), pain catastrophizing (Pain Catastrophizing Scale (PCS)), pain-related fear (Tampa Scale for Kinesiophobia (TSK-II)) and pain self-efficacy (Pain Self-Efficacy Questionnaire (PSEQ)) were administered in 85 persons with frozen shoulder. Correlation analyses assessed associations between pain-related beliefs and arm function. Regression analysis calculated the explained variance in arm function by pain-related beliefs.

Results: Pain-related fear, pain catastrophizing and pain self-efficacy were significantly associated with arm function $(r=0.5 \mathrm{I} ; r=0.45$ and $r=-0.69$, all $p<.000 \mathrm{I}$, respectively). Thirty-one percent of variance in arm function was explained by control variables, with pain intensity being the only significant one. After adding TSK-II, PCS and PSEQ scores to the model, $26 \%$ extra variance in arm function was explained, with significant contributions of pain intensity, pain-related fear and pain self-efficacy $\left(R^{2}=0.57\right)$.

Conclusions: Attention should be paid towards the negative effect of pain-related fear on outcomes in frozen shoulder and towards building one's pain self-efficacy given its protective value in pain management.

\section{Keywords}

adhesive capsulitis, fear of movement, disability, psychological factors, pain beliefs, frozen shoulder

Date received: 18th December 2019; revised: 2nd April 2020; accepted: 4th April 2020

\section{Introduction}

Frozen shoulder (FS) is a disorder at the glenohumeral joint, characterized by pain during active and passive joint movements (often severe), night pain and decreased active and passive joint motion. ${ }^{1,2}$ Movement restrictions generally occur in all movement planes, with more pain towards the end of the available joint motion and with more external rotation restrictions in elevated arm positions. ${ }^{2}$ Therefore, FS highly interferes with the independent performance of activities of daily living. ${ }^{2}$ While an incidence of FS of up to $5 \%$ is reported in the general population, ${ }^{2}$ exact incidence and prevalence rates are unknown given the lack of clear diagnostic criteria for FS. ${ }^{3}$ Structural changes are traditionally described as the main cause for the clinical features of FS. However, recent research additionally postulates muscle guarding as an underlying reason for

\footnotetext{
'REVAL Rehabilitation Research, Faculty of Rehabilitation Sciences, Hasselt University, Diepenbeek, Belgium

${ }^{2}$ Health Psychology Research, Faculty of Psychology and Educational Sciences, KU Leuven, Leuven, Belgium

${ }^{3}$ Experimental Health Psychology, Faculty of Psychology and Neuroscience, Maastricht University, Maastricht, The Netherlands

Corresponding author:

L De Baets, Hasselt University, Agoralaan Building A, 3590 Diepenbeek, Belgium.

Email: Liesbet.debaets@uhasselt.be
} 
decreased glenohumeral motion in FS, implicating that psychological factors such as anxiety or painrelated fear might be related to decreased motion. ${ }^{4}$ Although FS is described in relation to diabetes, thyroid disorders, cardiovascular diseases and Dupuytren disease, a significant number of individuals are still diagnosed with idiopathic FS. ${ }^{5}$ This indicates that the exact patho-etiological mechanisms underlying the development of FS are poorly understood. Therefore, the diagnosis of FS is based on clinical features, i.e. by investigating the pain and shoulder range of motion, and treatment is mainly symptomatic, i.e. by addressing pain intensity and stiffness. ${ }^{6,7}$

FS is historically described as a self-limiting disease, evolving through different phases with eventually a recovery within 12 to 18 months. ${ }^{8} 9$ However, mild symptoms may persist for several years in small groups of people with FS, with patients with diabetes mellitus having the worse outcomes. ${ }^{10,11}$ In this context, qualitative research revealed that apart from pain, the reduced function resulting from the inability to use the arm normally in their daily lives is an important concern for persons with FS. ${ }^{12}$ Therefore, it is suggested that the identification of the factors leading to a reduced arm function is critical to optimize the medical and physiotherapeutic management for persons with FS.

Recently, several systematic reviews have shown an association between pain-related beliefs and disability in persons receiving either surgery, conservative medical or physiotherapy treatment for shoulder pain. ${ }^{13-15}$ Pain self-efficacy was recognized as an important factor associated with arm function, assessed by the Shoulder Pain and Disability Index (SPADI) and Quick Disabilities of the Arm, Shoulder and Hand Questionnaire (QuickDASH), in persons who received physiotherapy for their shoulder complaint. ${ }^{16,17}$ This indicates that a person's perceived function may be related to the confidence he/she has in performing a task or activity despite pain. ${ }^{16,17}$ Regarding beliefs related to the fear-avoidance model (FAM) of pain, i.e. pain catastrophizing and pain-related fear, inconclusive results regarding their role in perceived arm function following shoulder treatment were reported. ${ }^{18-20}$ Of importance, none of the studies outlined in the systematic reviews included a sample of persons with FS. Given the recently proposed contribution of muscle guarding underlying the glenohumeral movement restrictions in persons with FS, together with the clinical signs of severe and long-lasting pain and dysfunction, it is important to examine the extent to which protective versus unhelpful pain-related beliefs may be underlying a reduced arm function in persons with FS.

Gaining insights in the extent to which pain-related beliefs contribute to variance in arm function in persons with FS would be informative for clinical practice, by providing medical and physiotherapeutic management opportunities. The aim of this study is therefore to explore the association between painrelated beliefs and perceived arm function in persons with FS. Secondary, this study aims to explore the variance in perceived arm function that can be explained by pain-related beliefs in persons with FS. It is hypothesized that pain-related fear, pain catastrophizing and pain self-efficacy are associated with perceived arm function, and that they will explain a significant proportion of the variance in perceived arm function in persons with FS.

\section{Methods}

\section{Participants}

Participants in this study were recruited by the researchers via orthopedic surgeons, private general practitioners' and physical therapists' practices in Belgium (period of recruitment February 2017December 2018). Individuals were included when they were adults with unilateral, clinically diagnosed FS. Therefore, they needed to have a passive range of motion restriction (measured using goniometry) at the affected shoulder of $25 \%$ or more in at least two directions in comparison to the unaffected shoulder, plus an external rotation restriction at the affected shoulder of at least $50 \%$ when compared to the unaffected side. ${ }^{2}$ Additional criteria were: pain and restricted range of motion present for at least two months, reaching a plateau or becoming worse ${ }^{2}$ and a gradual onset of pain and stiffness. Participants had to be able to fill in questionnaires in Dutch. Participants were excluded in case they already received a surgical procedure for their FS or had a systemic or neurological disease. All participants provided written informed consent before participation, as approved by the Medical Ethical Committee of Jessa Hospital Belgium. The procedures conformed to the Helsinki Declaration.

\section{Procedure}

During the consultation, all persons who met the inclusion criteria received information about the study. A member of the research team who was on the recruitment site verified the inclusion criteria, provided additional information when needed and asked the eligible persons to read and sign the informed consent form when they were willing to participate. Participants filled in the questionnaires immediately following their consultation, in a quiet room. Once completed, a researcher reviewed the questionnaire to confirm there were no missing answers. Participants did not receive any financial compensation. 


\section{Measures}

Sociodemographic information was collected (age, sex, race, affected side, duration of symptoms) and the following validated questionnaires were completed by each participant.

Disability of the Arm, Shoulder and Hand Questionnaire ${ }^{21,22}$. The Disabilities of the Arm, Shoulder and Hand Questionnaire (DASH) is a 30-item, self-report questionnaire developed to measure the disability experienced by people with disorders in the upper limb. Each item is scored on a five-point Likert scale. Response options for each item range from "no difficulty" to "unable". Scores are expressed as a percentage, where $0 \%$ represents no disability and $100 \%$ represents maximum disability. In the present study, the DASH was used to assess perceived arm function.

Tampa Scale for Kinesiophobia ${ }^{23,24}$. The Tampa Scale for Kinesiophobia (TSK-11) is a shortened version of the original 17-item TSK-11. This 11-item questionnaire measures the extent to which a person believes that physical activity or movement may lead to (re)-injury. Patients rate each item on a four-point Likert scale, with scoring alternatives ranging from "strongly disagree" to "strongly agree". Scores range from 11 to 44 with a higher score reflecting greater pain-related fear.

Pain Catastrophizing Scale ${ }^{25,26}$. The Pain Catastrophizing Scale (PCS) is a 13-item scale to quantify negative thoughts that may be experienced in the presence of pain. Each question is scored on a five-point Likert scale (from "not at all" to "always"). The total score of the PCS ranges between 0 and 52 with a higher score indicating greater pain catastrophizing. ${ }^{27}$

Pain self-efficacy questionnaire ${ }^{28}$. The Pain Self-Efficacy Questionnaire (PSEQ) is a 10-item scale which assesses a person's confidence in the ability to perform a task or activity, despite the pain. Each item is scored on a seven-point Likert scale (from "not at all confident" to "completely confident"). The total score ranges from 0 to 60 with a higher score representing greater pain self-efficacy beliefs.

Numeric Pain Rating Scale ${ }^{29}$. The Numeric Pain Rating Scale is an 11-point numeric rating scale, to indicate the shoulder pain intensity, with $0=$ no pain at all and $10=$ worst imaginable pain. Participants were asked to score their average shoulder pain intensity over the last week.

\section{Statistical analysis}

Statistical analysis was performed using JMP Pro (12.0, SAS Institute Inc., Cary, USA). Baseline data were analyzed to describe participants' characteristics. Data normality was verified using the ShapiroWilt test. To determine the association between painrelated fear, pain catastrophizing, pain self-efficacy and perceived arm function, Pearson (normal data distribution) or Spearman (not normally distributed data) correlation coefficients were calculated. Correlation coefficients of $0-0.29$ were considered very weak; $0.3-0.49$ weak; $0.5-0.69$ moderate, $0.7-$ 0.89 high; $0.9-1.0$ very high. ${ }^{30}$ The contribution of pain-related fear, pain catastrophizing and pain selfefficacy to the variance in perceived arm function was assessed using a multiple linear regression model with the DASH score as dependent variable. Multiple control variables (sex, age, pain intensity, duration of symptoms) were first added to the model to examine the variance in perceived arm function determined by the control variables. Thereafter, measures of painrelated fear (TSK-11), pain catastrophizing (PCS) and pain self-efficacy (PSEQ) were added to the control variables to assess their contribution to the variance in perceived arm function. Parameter estimates and adjusted coefficients of determination $\left(\mathrm{R}^{2}\right.$ adjusted) were calculated. Assumptions for linear regression were checked.

\section{Results}

\section{Participants}

A convenience sample of 85 persons (mean age (SD): $55.2(7.0) ; 59$ women $(69 \%)$ ) participated in this study. The mean duration of complaints (SD) was 4.6 (2.3) months. The dominant side was the affected side in 30 participants $(35 \%)$ and all participants were Caucasian. The mean pain intensity (SD) was 5.6 out of $10(2.5)$.

\section{Scores on the series of questionnaires}

In Table 1, an overview of the scores on the patientreported questionnaires is provided.

\section{Results of the correlation analyses}

Highly significant moderate associations were found between pain-related fear and pain self-efficacy and perceived arm function $(r=0.51, p<.0001$ and $r=-0.69$, $\mathrm{p}<.0001$, respectively). A highly significant weak relation was found between pain catastrophizing and perceived arm function $(r=0.45, p<.0001)$. A correlation matrix is given in Table 2 . 
Table I. Participants' outcomes on the questionnaires $(n=85)$.

\begin{tabular}{|c|c|c|}
\hline \multirow{2}{*}{$\begin{array}{l}\text { Perceived arm function } \\
\text { (DASH - range } 0-100)\end{array}$} & Mean (SD) & $4 \mathrm{I} . \mathrm{I}(\mathrm{I} 8.7)$ \\
\hline & Range & $3-77$ \\
\hline \multirow{2}{*}{$\begin{array}{l}\text { Pain intensity } \\
\text { (VAS 0-10), mean (SD) }\end{array}$} & Mean (SD) & $5.6(2.2)$ \\
\hline & Range & $2-10$ \\
\hline \multirow{2}{*}{$\begin{array}{l}\text { Pain-related fear } \\
\qquad \text { (TSK-I I - range II-44) }\end{array}$} & Mean (SD) & $24.2(6.1)$ \\
\hline & Range & $13-38$ \\
\hline \multirow{2}{*}{$\begin{array}{l}\text { Pain self-efficacy } \\
\text { (PSEQ - range 0-60) }\end{array}$} & Mean (SD) & 46.9 (II.9) \\
\hline & Range & $21-60$ \\
\hline \multirow{2}{*}{$\begin{array}{l}\text { Pain catastrophizing } \\
\text { (PCS - range 0-52) }\end{array}$} & Mean (SD) & I3.8 (9.8) \\
\hline & Range & $0-38$ \\
\hline
\end{tabular}

DASH: Disability of the Arm, Shoulder and Hand Questionnaire; VAS: Visual Analogue Scale; TSK-II: Tampa Scale for Kinesiophobia; PSEQ: Pain Self-Efficacy Questionnaire; PCS: Pain Catastrophizing Scale.

Table 2. Correlation matrix indicating the relation between perceived arm function and pain-related beliefs, and the relation among the different pain-related beliefs.

\begin{tabular}{|lcccc|}
\hline & DASH & TSK-II & PCS & PSEQ \\
\hline DASH & & $0.5 I^{*}$ & $0.45^{*}$ & $-0.69^{*}$ \\
\hline TSK-II & $0.5 I^{*}$ & & $0.55^{*}$ & $-0.46^{*}$ \\
\hline PCS & $0.45^{*}$ & $0.55^{*}$ & & $-0.58^{*}$ \\
\hline PSEQ & $-0.69^{*}$ & $-0.46^{*}$ & $-0.58^{*}$ & \\
\hline
\end{tabular}

DASH: Disability of the Arm, Shoulder and Hand Questionnaire; VAS: Visual Analogue Scale; TSK-II: Tampa Scale for Kinesiophobia; PSEQ: Pain Self-Efficacy Questionnaire; PCS: Pain Catastrophizing Scale. $* \mathrm{p}<.0001$.

\section{Results of the regression analyses}

The results of the regression analyses are presented in Table 3. By only including control variables in the model, $31 \%$ of the variance in function was explained. Pain intensity was the only significant control variable in the model, with increased pain intensity associated with reduced perceived arm function. When painrelated fear, pain catastrophizing and pain self-efficacy were added to this model, pain-related fear and pain self-efficacy were identified as significant contributors to the variance in perceived arm function, next to pain intensity. The model explained a total of $57 \%$ of the variance in perceived arm function.

\section{Discussion}

The aim of this study was to examine whether perceived arm function in a sample of persons with FS was associated with pain-related fear, pain catastrophizing and pain self-efficacy. For that purpose, these pain-related beliefs were included as independent variables in a regression analysis, together with demographics (duration of symptoms, age, sex) and pain intensity, as these control variables have been shown to be associated with arm function in the existent literature. ${ }^{31}$ Each painrelated belief was significantly associated with perceived arm function, and pain-related fear and pain selfefficacy furthermore significantly explained an additional proportion of variance in function $(26 \%)$. The results thereby confirm our hypothesis, and highlight that apart from pain intensity, beliefs towards pain or painful activities are also associated with perceived arm function.

Within the FAM, catastrophic thoughts about pain following a pain experience are believed to be a precursor for pain-related fear and avoidance behavior. This avoidance behavior in turn can lead to decreased function. ${ }^{32}$ Given the cross-sectional design of this study, it is not possible to infer a causal relationship between pain-related beliefs and perceived function. However, it is clear that patients' perception of their ability to perform an activity is not only associated with the individual's level of pain but also with the negative beliefs about pain, and with the individual's belief that the activity can cause pain or do harm.

Regarding pain catastrophizing, studies have shown a cutoff value of 30 on the PCS to be associated with clinical relevance. ${ }^{27}$ The average PCS score of 13.8 (9.8) in this sample is thus considered very low, which might indicate that persons with FS do not generally show these catastrophic interpretations regarding the pain experience. ${ }^{27}$ Coronado et al. revealed in a cross-sectional study in persons with unilateral shoulder pain that optimism moderated the effect of pain catastrophizing on shoulder function. ${ }^{33}$ Similarly, Hood et al. reported that low levels of hope and optimism were associated with increased pain catastrophizing during a cold-pressure task. ${ }^{34}$ It is possible that the fairly predictable course of the recovery of the FS created hope and optimism in this sample of persons with FS, leading to the low scores on the PCS and the fact that pain catastrophizing did not significantly explain variance in perceived arm function. Additionally, the relatively short mean duration since the FS diagnosis in this study sample (i.e. 4.5 months) might be related to higher levels of optimism and lower levels of pain catastrophizing. However, since this is the first study assessing catastrophic thoughts about pain in persons with FS, results should be confirmed in future studies. 
Table 3. Regression model indicating the variance in perceived arm function explained by control variables and pain-related beliefs in persons with frozen shoulder.

\begin{tabular}{|c|c|c|c|c|c|c|c|}
\hline Regression model & Variables & Std Beta & $\mathrm{p}$-Value & VIF & $\mathrm{R}^{2}$ & $R^{2}$ adj & $\Delta R^{2}$ adj \\
\hline \multirow{4}{*}{$\begin{array}{l}\text { Model with control } \\
\text { variables }\end{array}$} & Sex & 0.14 & 0.12 & 1 & 0.34 & 0.31 & \\
\hline & Age & -0.01 & 0.96 & 1 & & & \\
\hline & Duration of symptoms & -0.05 & 0.56 & 1.1 & & & \\
\hline & Pain intensity & 0.56 & $<0.0001$ & I & & & \\
\hline \multirow{7}{*}{$\begin{array}{l}\text { Control variables + TSK-II, } \\
\text { PCS and PSEQ }\end{array}$} & Sex & 0.09 & 0.21 & 1.1 & 0.61 & 0.57 & 0.26 \\
\hline & Age & 0.04 & 0.52 & I.I & & & \\
\hline & Duration of symptoms & -0.04 & 0.53 & 1.1 & & & \\
\hline & Pain intensity & 0.29 & 0.0005 & 1.3 & & & \\
\hline & TSK-II & 0.23 & 0.01 & 1.6 & & & \\
\hline & PCS & 0.09 & 0.35 & 1.9 & & & \\
\hline & PSEQ & -0.5 & $<0.0001$ & 1.7 & & & \\
\hline
\end{tabular}

DASH: Disability of the Arm, Shoulder and Hand Questionnaire; VAS: Visual Analogue Scale; TSK-I I: Tampa Scale for Kinesiophobia; PSEQ: Pain SelfEfficacy Questionnaire; PCS: Pain Catastrophizing Scale; VIF: variance inflation factor.

Results on the association between pain-related fear and function are conflicting in the shoulder-related literature. Clausen et al. found no predictive value of TSK-11 scores on SPADI-function, ${ }^{20}$ and Lentz et al. reported that pain-related fear only explained a very small amount of the variance $(3 \%)$ in SPADI scores in persons with unilateral shoulder pain. ${ }^{19}$ In contrast, our results are in line with the results reported by Kromer et al. who reported a predictive value of pain-related fear, measured with the fear-avoidance beliefs questionnaire, on disability in persons with subacromial pain. ${ }^{18}$ In their study, pain-related fear explained an additional $9 \%$ of the variance in function scores beyond age, sex and pain intensity. ${ }^{18}$ The avoidance or the fearful reaction towards the performance of painful activities might be interpreted as a normal reaction to persistent pain. ${ }^{35}$ Given that persons with FS have movement restrictions in all movement planes for a long duration, with typically high levels of pain increasing towards the end of the available range of motion, ${ }^{2}$ it is not surprising that pain and pain-related fear account for variance in arm function in persons with FS.

The strongest association with perceived arm function was found for pain self-efficacy. The self-efficacy construct is described by Bandura in 1977 within the social cognitive theory as a person's belief in his/her ability to succeed in specific situations or to accomplish a task. ${ }^{36}$ According to Bandura's theory, people with high self-efficacy are confident in their abilities, and are therefore more likely to approach challenging tasks or activities as something to accomplish or to succeed in, rather than as something to fear or avoid. ${ }^{37}$ Pain selfefficacy beliefs include beliefs regarding the ability to control both pain and the negative emotions associated with it, to perform daily activities (household, work activities) despite the pain, to implement advice from healthcare professionals and to define individual needs, goals and preferences. ${ }^{38}$ The strong association between arm function and pain self-efficacy indicates that the individual's perception or belief in his/her abilities is related to the functioning of the arm to a large extent. It must however be acknowledged that the high association with the disability measure in the current study may be somewhat inflated by item overlap, as some of the DASH items resemble items on the PSEQ, but in the opposite direction. For example, items 1, 4 and 7 of DASH on abilities to open a jar, to prepare a meal and to do heavy household chores might resemble item 2 of the PSEQ on the confidence to do most of the household chores (e.g. tidying-up, washing dishes, etc.) despite the pain. Item 23 of DASH which asks whether limitations at work or during other regular daily activities were experienced as a result of arm, shoulder or hand problems is potentially similarly interpretable as item 5 of PSEQ, measuring 
the confidence to do some work, despite the pain. In order to explore the potential effect of the item overlap between DASH and PSEQ, we removed items 2 and 5 from the PSEQ and calculated the explained variance in arm function by the control variables, TSK-11 scores, PCS scores and the adjusted PSEQ score again. $\mathrm{R}^{2}$ was in this case $55 \%$ instead of $57 \%$, and the same standard Beta for PSEQ was found, indicating that the item overlap had only a limited effect on the explained variance in function.

\section{Limitations}

Since the exact etiology of FS is still unknown, there is no gold standard for the diagnosis of this condition which is, therefore, primarily based on clinical criteria. ${ }^{2,39}$ Moreover, the differentiation of FS from other shoulder disorders is difficult in the initial stage. ${ }^{1}$ Since we only included patients with a gradual onset of symptoms, which were stable or got worse, and were present for longer than two months, it is unlikely that we recruited persons with a shoulder condition other than FS. Furthermore, we did not use any physical tests for the assessment of arm functioning, but relied on self-report (DASH). Since perceived and actual functioning may diverge significantly in different musculoskeletal complaints, ${ }^{40}$ the results of the effects of pain-related beliefs on reported function should be interpreted with caution. Furthermore, given the lack of physical variables in the reported prediction model, the reported explained variance in perceived arm function should be interpreted with care as this might overestimate the role of pain beliefs in this population. Given the cross-sectional design of this observational study, no conclusions can be drawn with regard to how pain-related beliefs evolve during the clinical course of persons with FS. Therefore, the cause-consequence relationship between pain intensity, pain-related beliefs and potential persistent disability is not clear at this moment.

\section{Clinical implications and future research}

Healthcare professionals need to acknowledge the value of pain-related fear and pain self-efficacy in the assessment of persons with FS, as these pain-related beliefs may be associated with disability. Therefore, these constructs should be included in the regular assessment of persons with FS in medical and physiotherapy care. Screening tools which support a multidimensional examination such as the modified version of the STarT Back Screening Tool, ${ }^{41}$ the Örebro Musculoskeletal Pain Screening Questionnaire-short version ${ }^{42}$ or the Optimal Screening for Prediction of Referral and Outcome Yellow Flag Assessment Tool can be used. ${ }^{43}$
Other validated questionnaires recording one or several pain-related beliefs that can be used in clinical practice are the TSK, the PCS, the PSEQ or the recently developed Fear-Avoidance Component Scale, ${ }^{23,27,28,44}$ which assesses all cognitive, emotional and behavioral components related to the updated version of the FAM. ${ }^{44}$ Apart from the relation between pain-related beliefs and perceived arm function, it would be of interest to assess the relation between objectively measured arm function and pain-related beliefs in future studies in order to limit the possible confounding effect of similarities in the questionnaires on perceived arm function and self-efficacy. Furthermore, investigating the association between maladaptive pain-related beliefs and effective avoidance behavior in terms of adapted motor behavior (i.e. adapted glenohumeral and scapulothoracic range of motion, and altered muscle activation patterns) in persons with FS might additionally explain the relationship between pain-related beliefs and reduced arm function.

Regarding the management options for persons with FS, a recent systematic review indicated a gap in the literature towards the non-surgical management of $\mathrm{FS}^{45}$ In other musculoskeletal pain conditions, such as nonspecific low back pain, pain-related beliefs are identified as mediating factors for treatment success. ${ }^{46}$ Therefore, it is of interest to assess the value of management strategies accompanied by biopsychosocial interventions which create awareness for the association between pain-related beliefs and perceived arm function, and to prepare patients with inadequate pain-related beliefs for what they can expect regarding their recovery (understanding pain, unhelpful thoughts, coping styles and goal setting). ${ }^{47-49}$ It is furthermore relevant to assess the value of self-management support and well-guided physical activity in the management of FS, as an important effect of self-management support and supported physical activity interventions is assumed to be the improvement of an individual's pain-related beliefs and a patient's independence to manage his/her complaints. ${ }^{50,51}$ From that point of view, it is advisable to additionally investigate the effect of physical activity interventions, based on individual goal-setting and preferences, as a reinforcement strategy in the (self-)management of pain and function in persons with FS. In this context, it is of additional importance to acknowledge the value of behavioral change techniques to improve self-efficacy beliefs. $^{52,53}$

\section{Conclusion}

This is the first study assessing pain-related beliefs in a sample of persons with FS. In addition to pain intensity, pain-related fear and pain self-efficacy were 
shown to significantly explain variance in perceived arm function in persons with FS. These results indicate that the assessment of persons with FS should take these constructs into account in order to optimize the medical, psychological and physiotherapeutic management of FS.

\section{Authors' note}

This article is not based on a previous communication to a society or meeting.

\section{Authors' contribution}

LDB and AT researched the literature and conceived the study. LDB, TM, JT, JWSV AT were involved in protocol development, gaining ethical approval, patient recruitment and data analysis. LDB, TM, AT, JT, JWSV wrote the first draft of the article. All authors reviewed and edited the article and approved the final version of the article.

\section{Declaration of Conflicting Interests}

The author(s) declared no potential conflicts of interest with respect to the research, authorship, and/or publication of this article.

\section{Ethical Review and Patient Consent}

Ethical approval to report this case/these cases was obtained from the local Ethics Committee of Hasselt University and Jessa Hospital, Belgium (17.08/REVA17.01). Written informed consent was obtained from the patient(s) for their anonymized information to be published in this article. Written informed consent was obtained from all subjects before the study.

\section{Funding}

The author(s) received no financial support for the research, authorship, and/or publication of this article.

\section{ORCID iD}

L De Baets (D) https://orcid.org/0000-0002-1370-2090

\section{References}

1. Walmsley S, Osmotherly PG and Rivett DA. Movement and pain patterns in early stage primary/idiopathic adhesive capsulitis: a factor analysis. Physiotherapy 2014; 100 : 336-343.

2. Kelley MJ, Shaffer MA, Kuhn JE, et al. Shoulder pain and mobility deficits: adhesive capsulitis. J Orthop Sports Phys Ther 2013; 43: A1-A31.

3. Lewis J. Frozen shoulder contracture syndrome aetiology, diagnosis and management. Man Ther 2015; 20: 2-9.

4. Hollmann L, Halaki M, Kamper SJ, et al. Does muscle guarding play a role in range of motion loss in patients with frozen shoulder? Musculoskelet Sci Pract 2018; 37: 64-68.
5. Ryan V, Brown H, Minns Lowe CJ, et al. The pathophysiology associated with primary (idiopathic) frozen shoulder: a systematic review. BMC Musculoskelet Disord 2016; 17: 340.

6. Hanchard NC, Goodchild L, Thompson J, et al. A questionnaire survey of UK physiotherapists on the diagnosis and management of contracted (frozen) shoulder. Physiotherapy 2011; 97: 115-125.

7. Maund E, Craig D, Suekarran S, et al. Management of frozen shoulder: a systematic review and cost-effectiveness analysis. Health Technol Assess 2012; 16: 1-264.

8. Hannafin JA and Chiaia TA. Adhesive capsulitis: a treatment approach. Clin Orthop Relat Res 2000; 372: 95-109.

9. Wong CK, Levine WN, Deo K, et al. Natural history of frozen shoulder: fact or fiction? A systematic review. Physiotherapy 2017; 103: 40-47.

10. Griggs SM, Ahn A and Green A. Idiopathic adhesive capsulitis. A prospective functional outcome study of nonoperative treatment. J Bone Joint Surgery Am 2000; 82: 1398-1407.

11. Shaffer B, Tibone JE and Kerlan RK. Frozen shoulder. A long-term follow-up. J Bone Joint Surg Am 1992; 74: 738-746.

12. Jones S, Hanchard $\mathrm{N}$, Hamilton $\mathrm{S}$, et al. A qualitative study of patients' perceptions and priorities when living with primary frozen shoulder. BMJ Open 2013; 3: e003452.

13. Coronado RA, Seitz AL, Pelote E, et al. Are psychosocial factors associated with patient-reported outcome measures in patients with rotator cuff tears? A systematic review. Clin Orthop Relat Res 2018; 476: 810-829.

14. De Baets L, Matheve T, Meeus M, et al. The influence of cognitions, emotions and behavioral factors on treatment outcomes in musculoskeletal shoulder pain: a systematic review. Clin Rehab 2019; 33: 980-991.

15. Martinez-Calderon J, Struyf F, Meeus M, et al. The association between pain beliefs and pain intensity and/or disability in people with shoulder pain: a systematic review. Musculoskelet Sci Pract 2018; 37: 29-57.

16. Chester R, Jerosch-Herold C, Lewis J, et al. Psychological factors are associated with the outcome of physiotherapy for people with shoulder pain: a multicentre longitudinal cohort study. Brit J Sports Med 2018; 52: 269-275.

17. Chester R, Khondoker M, Shepstone L, et al. Selfefficacy and risk of persistent shoulder pain: results of a Classification and Regression Tree (CART) analysis. Brit J Sports Med 2019; 53: 825-834.

18. Kromer TO, Sieben JM, de Bie RA, et al. Influence of fear-avoidance beliefs on disability in patients with subacromial shoulder pain in primary care: a secondary analysis. Physical Ther 2014; 94: 1775-1784. 2014/07/26. DOI: $10.2522 /$ ptj.20130587.

19. Lentz TA, Barabas JA, Day T, et al. The relationship of pain intensity, physical impairment, and pain-related fear to function in patients with shoulder pathology. J Orthop Sports Phys Ther 2009; 39: 270-277. 2009/04/07. DOI: 10.2519/jospt.2009.2879.

20. Clausen MB, Witten A, Holm K, et al. Glenohumeral and scapulothoracic strength impairments exists in 
patients with subacromial impingement, but these are not reflected in the shoulder pain and disability index. $B M C$ Musculoskelet Disord 2017; 18: 302.

21. Hudak PL, Amadio PC and Bombardier C. Development of an upper extremity outcome measure: the DASH (disabilities of the arm, shoulder and hand) (corrected). The Upper Extremity Collaborative Group (UECG). Am J Ind Med 1996; 29: 602-608.

22. Beaton DE, Katz JN, Fossel AH, et al. Measuring the whole or the parts? Validity, reliability, and responsiveness of the Disabilities of the Arm, Shoulder and Hand outcome measure in different regions of the upper extremity. J Hand Ther 2001; 14(2): 128-146.

23. Woby SR, Roach NK, Urmston M, et al. Psychometric properties of the TSK-11: a shortened version of the Tampa Scale for Kinesiophobia. Pain 2005; 117: 137-144.

24. Mintken PE, Cleland JA, Whitman JM, et al. Psychometric properties of the Fear-Avoidance Beliefs Questionnaire and Tampa Scale of Kinesiophobia in patients with shoulder pain. Arch Phys Med Rehabil 2010; 91: 1128-1136.

25. Osman A, Barrios FX, Gutierrez PM, et al. The Pain Catastrophizing Scale: further psychometric evaluation with adult samples. J Behav Med 2000; 23: 351-365.

26. Osman A, Barrios FX, Kopper BA, et al. Factor structure, reliability, and validity of the Pain Catastrophizing Scale. J Behav Med 1997; 20: 589-605.

27. Sullivan MJL, Bishop SR and Pivik J. The Pain Catastrophizing Scale: Development and validation. Psychological Assessment 1995; 7: 524-532.

28. Nicholas MK. The pain self-efficacy questionnaire: taking pain into account. Eur J Pain (London, England) 2007; 11: 153-163.

29. Hawker GA, Mian S, Kendzerska T, et al. Measures of adult pain: Visual Analog Scale for Pain (VAS Pain), Numeric Rating Scale for Pain (NRS Pain), McGill Pain Questionnaire (MPQ), Short-Form McGill Pain Questionnaire (SF-MPQ), Chronic Pain Grade Scale (CPGS), Short Form-36 Bodily Pain Scale (SF-36 BPS), and Measure of Intermittent and Constant Osteoarthritis Pain (ICOAP). Arthritis Care Res 2011; 63: S240-252.

30. Rumsey DJ. Statistics for dummies. 2nd ed. Indiana: Wiley Publishing Inc., 2016.

31. Kuijpers T, van der Windt DA, Boeke AJ, et al. Clinical prediction rules for the prognosis of shoulder pain in general practice. Pain 2006; 120: 276-285.

32. Vlaeyen JW, Crombez G and Linton SJ. The fear-avoidance model of pain. Pain 2016; 157: 1588-1589.

33. Coronado RA, Simon CB, Lentz TA, et al. Optimism moderates the influence of pain catastrophizing on shoulder pain outcome: a longitudinal analysis. J Orthop Sports Phys Ther 2017; 47: 21-30.

34. Hood A, Pulvers K, Carrillo J, et al. Positive traits linked to less pain through lower pain catastrophizing. Pers Individ Dif 2012; 52: 401-405.
35. Meulders A. From fear of movement-related pain and avoidance to chronic pain disability: a state-of-the-art review. Curr Opin Behav Sci 2019; 26: 130-136.

36. Bandura A. Self-efficacy: toward a unifying theory of behavioral change. Psychol Rev 1977; 84: 191-215.

37. Marks R, Allegrante JP and Lorig K. A review and synthesis of research evidence for self-efficacy-enhancing interventions for reducing chronic disability: implications for health education practice (part I). Health Promot Pract 2005; 6: 37-43.

38. Miles CL, Pincus T, Carnes D, et al. Measuring pain selfefficacy. Clin J Pain 2011; 27: 461-470.

39. Roberts S, Dearne R, Keen S, et al. Routine X-rays for suspected frozen shoulder offer little over diagnosis based on history and clinical examination alone. Musculoskelet Care 2019; 17: 288-292.

40. Hidding A, van Santen M, De Klerk E, et al. Comparison between self-report measures and clinical observations of functional disability in ankylosing spondylitis, rheumatoid arthritis and fibromyalgia. J Rheumatol 1994; 21 : 818-823.

41. Butera KA, Lentz TA, Beneciuk JM, et al. Preliminary evaluation of a modified start back screening tool across different musculoskeletal pain conditions. Phys Ther 2016; 96: 1251-1261.

42. Nicholas MK, Costa DSJ, Linton SJ, et al. Predicting return to work in a heterogeneous sample of recently injured workers using the brief OMPSQ-SF. J Occup Rehabil 2019; 29: 295-302.

43. George SZ, Beneciuk JM, Lentz TA, et al. The Optimal Screening for Prediction of Referral and Outcome (OSPRO) in patients with musculoskeletal pain conditions: a longitudinal validation cohort from the USA. BMJ Open 2017; 7: e015188.

44. Neblett R, Mayer TG, Hartzell MM, et al. The Fear-Avoidance Components Scale (FACS): development and psychometric evaluation of a new measure of pain-related fear avoidance. Pain Pract 2016; 16: 435-450.

45. Minns Lowe C, Barrett E, McCreesh K, et al. Clinical effectiveness of non-surgical interventions for primary frozen shoulder: a systematic review. J Rehabil Med 2019; 51: 539-556.

46. Mansell G, Hill JC, Main CJ, et al. Mediators of treatment effect in the back in action trial: using latent growth modeling to take change over time into account. Clin $J$ Pain 2017; 33: 811-819.

47. van Erp RMA, Huijnen IPJ, Jakobs MLG, et al. Effectiveness of primary care interventions using a biopsychosocial approach in chronic low back pain: a systematic review. Pain Pract 2019; 19: 224-241.

48. Sawyer EE, McDevitt AW, Louw A, et al. Use of pain neuroscience education, tactile discrimination, and graded motor imagery in an individual with frozen shoulder. J Orthop Sports Phys Ther 2018; 48: 174-184. 
49. Watson JA, Ryan CG, Cooper L, et al. Pain neuroscience education for adults with chronic musculoskeletal pain: a mixed-methods systematic review and meta-analysis. $J$ Pain 2019; 20: 1140.e1-1140.e22.

50. Hutting N, Johnston V, Staal JB, et al. Promoting the use of self-management strategies for people with persistent musculoskeletal disorders: the role of physical therapists. J Orthop Sports Phys Ther 2019; 49: 212-215.

51. Lewis $\mathbf{J}$ and O'Sullivan P. Is it time to reframe how we care for people with non-traumatic musculoskeletal pain? Brit J Sports Med 2018; 52: 1543-1544.
52. O'Sullivan K, Dankaerts W, O’Sullivan L, et al. Cognitive functional therapy for disabling nonspecific chronic low back pain: multiple case-cohort study. Phys Ther 2015; 95: 1478-1488.

53. O'Sullivan PB, Caneiro JP, O'Keeffe M, et al. Cognitive functional therapy: an integrated behavioral approach for the targeted management of disabling low back pain. Phys Ther 2018; 98: 408-423. 